\title{
Influence of Experimental Parameters on Properties and Microstructure of the Steel X210CrW12 in the Semi-solid State
}

\author{
C. Fraipont ${ }^{1, a}$, W. Püttgen ${ }^{2, b}$, W. Bleck ${ }^{2, c}$ and J. Lecomte-Beckers ${ }^{1, d}$ \\ ${ }^{1}$ MMS (IMGC, Bât. B52), University of Liège, Sart-Tilman, 4000 Liège, Belgium \\ ${ }^{2}$ Institut für Eisenhüttenkunde, Rheinisch-Westfälische Technische Hochschule Aachen, \\ Intzestr. 1, 52072 Aachen, Germany \\ aceline.fraipont@ulg.ac.be, bwolfgang.puettgen@iehk.rwth-aachen.de, \\ cwolfgang.bleck@iehk.rwth-aachen.de, dJacqueline.lecomte@ulg.ac.be
}

Keywords: Thixoforming, SSM (Semi-Solid Metalforming), steel, thermo-mechanical behaviour, X210CrW12.

\begin{abstract}
This paper deals with the examination of the steel grade X210CrW12 and its suitability for Thixoforming. In the semi-solid state, the microstructure of this steel consists of a homogeneous distribution of globular particles surrounded by liquid. Additionally, carbides are stabile up to fraction liquid contents of approximately $40 \%$. After quenching, this steel reveals a globular austenitic microstructure with eutectic (former liquid phase) at the grain boundaries. Compression tests permit to determine the influence of different process parameters on the properties and the material behaviour in the semi-solid state. Their influence on the microstructure was investigated but not yet highlighted. Further investigations on this steel allow a fine-tuning to establish optimal process windows of the different thixoforming- and rheoforming- routes.
\end{abstract}

\section{Introduction}

Semi-solid metalforming allows to produce components of complex geometry in near-net-shape quality with economic advantages in comparison to casting and forging. Several processes were already developed for low melting materials, e.g. aluminium or magnesium [1,2]. But, this process can also become very interesting with regard to an application in the steel industry; if problems regarding suitable tools and materials to be thixoformed, adjusted heating strategies and automation are solved. This paper deals with the examination of material properties in the semi-solid state of the steel grade $\mathrm{X} 210 \mathrm{CrW} 12$.

\section{Materials}

As feedstock, hot-rolled material was used as displayed in Fig.1. It showed a microstructure which is composed of a martensitic matrix with embedded, uniformly, finedispersed carbides. The semi-solid interval, the characteristic temperatures for thixoforming and the solidification range were determined by DTA experiments [3]. The steel X210CrW12 fulfils a lot of parameters as they were recently summarized by Kasakov [4] for thixoforming processes: low solidus temperature, low liquid fraction sensitivity at thixoforming temperature and sufficiently wide semisolid interval. These properties permit the study of different parameters in the semi-solid state and a rather easy handling during the forming process. The chemical

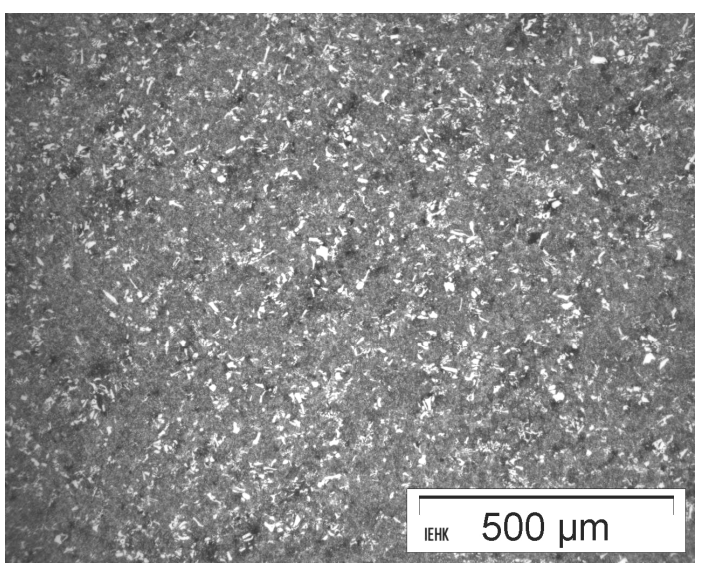

Figure. 1: Initial microstructure of X210CrW12 composition of the investigated material is given in Table 1. 


\begin{tabular}{|l|l|l|l|l|l|l|l|}
\hline$C \%$ & $\mathrm{Si} \%$ & $\mathrm{Mn} \%$ & $\mathrm{P} \%$ & $\mathrm{~S} \%$ & $\mathrm{Cr} \%$ & $\mathrm{Mo} \%$ & $\mathrm{Ni} \%$ \\
\hline 2,245 & 0,26 & 0,32 & 0,019 & 0,005 & 11,44 & 0,08 & 0,08 \\
\hline $\mathrm{Al} \%$ & $\mathrm{Co} \%$ & $\mathrm{Cu} \%$ & $\mathrm{Ti} \%$ & $V \%$ & $\mathrm{~W} \%$ & $\mathrm{Sn} \%$ & $\mathrm{Fe} \%$ \\
\hline 0,009 & 0,007 & 0,03 & 0,007 & 0,09 & 0,72 & 0,002 & 84,7 \\
\hline
\end{tabular}

Table 1: Chemistry of the steel X210CrW12, mass contents

Observations showed that the steel X210CrW12 consists in the semi-solid state of a homogeneous distribution of globular particles surrounded by liquid. After rapid cooling, the steel shows an austenitic globular microstructure with eutectic at the grain boundaries. Due to the high carbon content, the austenite is metastable after quenching and can transform during subsequent heat treatments. This can lead to totally new material properties as shown in [5]. Furthermore, the amount of austenite allows a roughly determination of the liquid fraction content adjusted in the semi-solid state with adapted imaging analyze program rather easily.

\section{Experiments}

Compression tests were done in a hot deformation simulator as displayed in Fig.2. Cylindrical samples with a height of $30 \mathrm{~mm}$ and a diameter of $20 \mathrm{~mm}$, Fig.3., were heated inside an inductor and deformed between two pistons made of silicon nitride. Between the pistons and the sample, small plates of molybdenum were placed to reduce heat losses and to achieve a more homogeneous temperature distribution inside the sample. The temperature was measured and controlled with an external thermocouple on the sample surface. Different parameters were varied in the experiments: forming temperature $\left(1150^{\circ} \mathrm{C}\right.$ to $\left.1270^{\circ} \mathrm{C}\right)$, deformation $(0$ to $5 \mathrm{~mm})$, deformation rate $(0,5$ to $10 \mathrm{~mm} / \mathrm{s}$ ), heating rate $(1$ to $50 \mathrm{~K} / \mathrm{s}$ ) and holding time (30 to $120 \mathrm{~s})$. Fig.3 shows the approximate course of temperature and the point of deformation. The temperature in the sample was measured with two thermocouples in the middle of the sample and on the surface as displayed in Fig.4. The figure shows that the time to reach the desired temperature in the centre is greater than at the surface and increases roughly $5 \mathrm{~K}$ above the target temperature. After quenching the samples with a constant argon flow of $51 / \mathrm{min}$, the samples were investigated metallographically. Since the sample was only in the middle in the semi-solid state, only small deformations were performed.

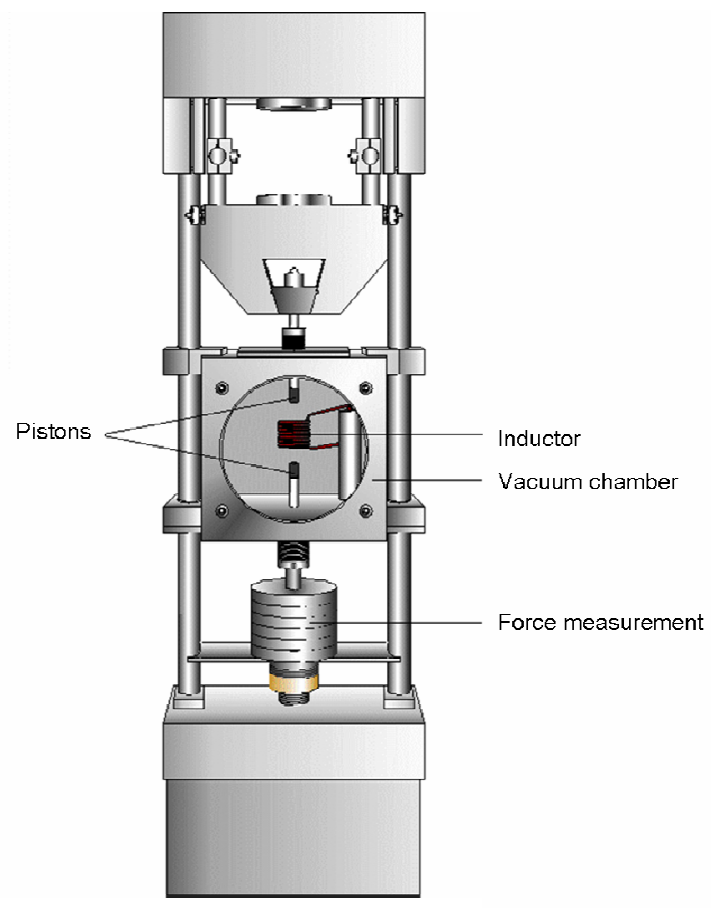

Figure. 2: Compression test

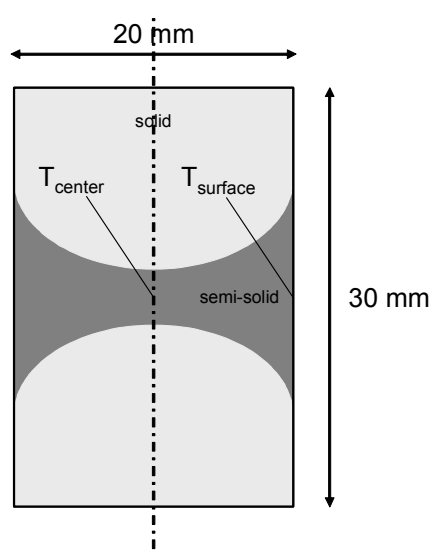

Figure. 3: Geometry of the samples and resulting microstructure inside the sample 


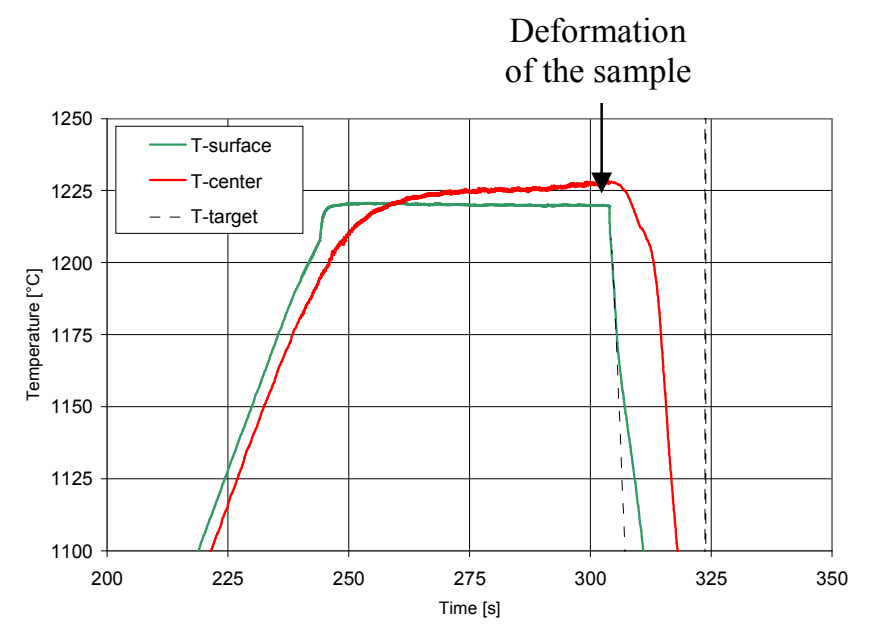

Figure. 4: Temperature evolution during the experiment.

\section{Results}

The influence of the different parameters on the load-deformation-diagram is summarized in Fig.5. The maximum on each curve corresponds to a breakdown of the solid skeleton in the samples. All results are compared with a reference curve. This reference curve corresponds to a test which was performed at a temperature of $1240^{\circ} \mathrm{C}$, deformation rate of $2 \mathrm{~mm} / \mathrm{s}$, heating rate of $5 \mathrm{~K} / \mathrm{s}$ and holding time of $60 \mathrm{~s}$. An increase in forming temperature and holding time lead to a decrease of the load needed to compress the sample. In contrary, an increase of deformation rate and of heating rate leads to an increase of the load. These results can be explained as follows: Higher temperatures increase the amount of liquid phase so that less load is needed for deformation. For temperatures where the material is still in the solid state, the curves are similar to simple hot compression curves for steels which is not displayed in the figure.

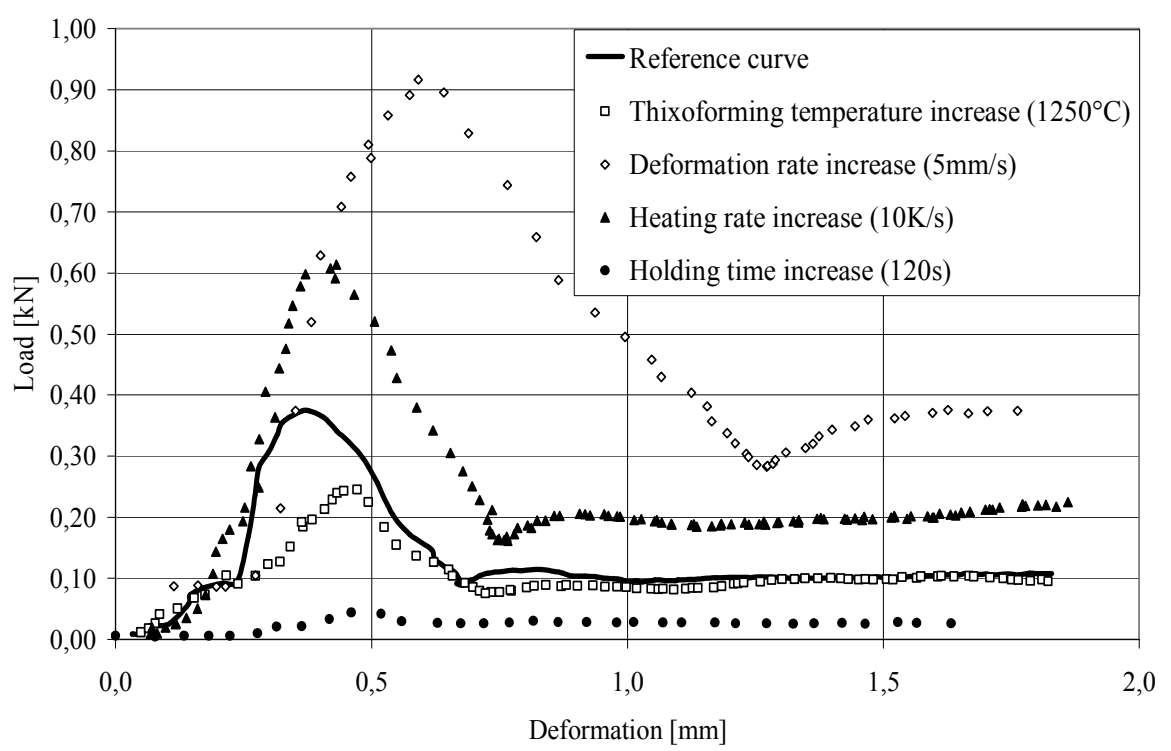

Figure. 5: Influence of the different parameters on the load-displacementdiagram in comparison to a reference curve $\left(1240^{\circ} \mathrm{C} ; 2 \mathrm{~mm} / \mathrm{s} ; 5 \mathrm{~K} / \mathrm{s} ; 60 \mathrm{~s}\right)$
Longer holding times lead to a more globular microstructure with a higher amount of liquid which results in a reduction of the load. Variations in the deformation rate result in different time for the solid particles to glide correctly. So, when the deformation rate increases, the needed load to achieve the same deformation is bigger. Additionally, the deformation corresponding to the maximal load is larger. Greater heating rates lead to lower amounts of liquid

phase because the time to build it up, is reduced. Therefore, the load which is needed to deform the sample is bigger because there is more solid with a stronger skeleton which is harder to deform than the reference sample. The influence of the temperature on the microstructure is displayed in Fig.6 for three different temperatures. The higher the temperature is, the more globular the grains become and the more liquid phase appears, the structure becomes better for the semi-solid metalforming. The load to destroy the solid skeleton as a function of temperature and measured fraction liquid contents is displayed in Fig.7. The load decreases with increasing temperature which corresponds to the formation of liquid phase which was determined beforehand via DTA and afterwards on 
quenched specimens via light microscopy. Between 1220 and $1230^{\circ} \mathrm{C}$ the necessary load to destroy the skeleton decreases rapidly although only minor changes in the fraction liquid content were measured.
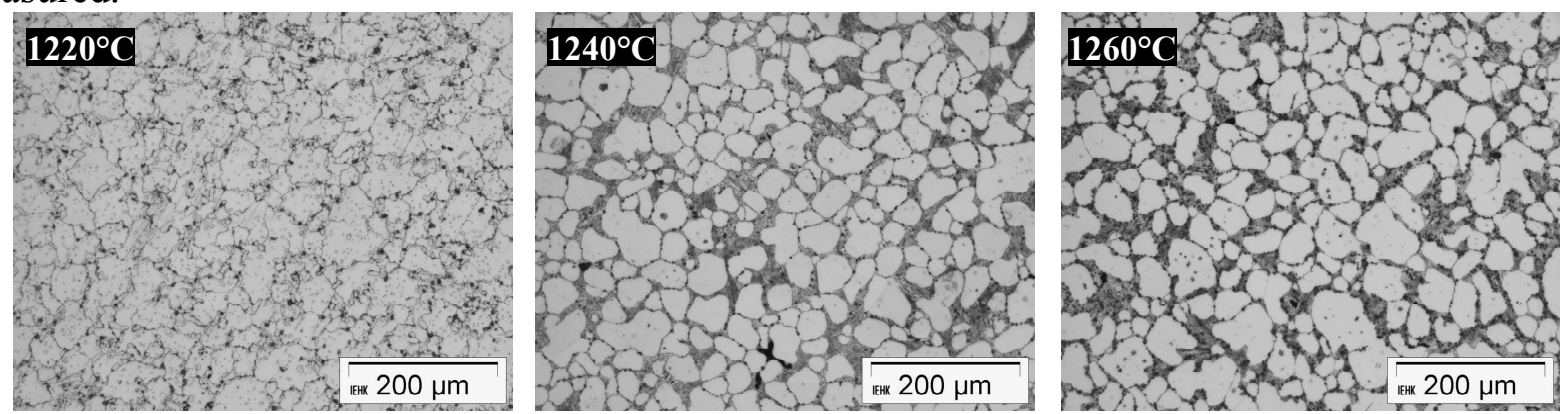

Figure. 6: Microstructure evolution at temperatures of 1220,1240 and $1260^{\circ} \mathrm{C}$.

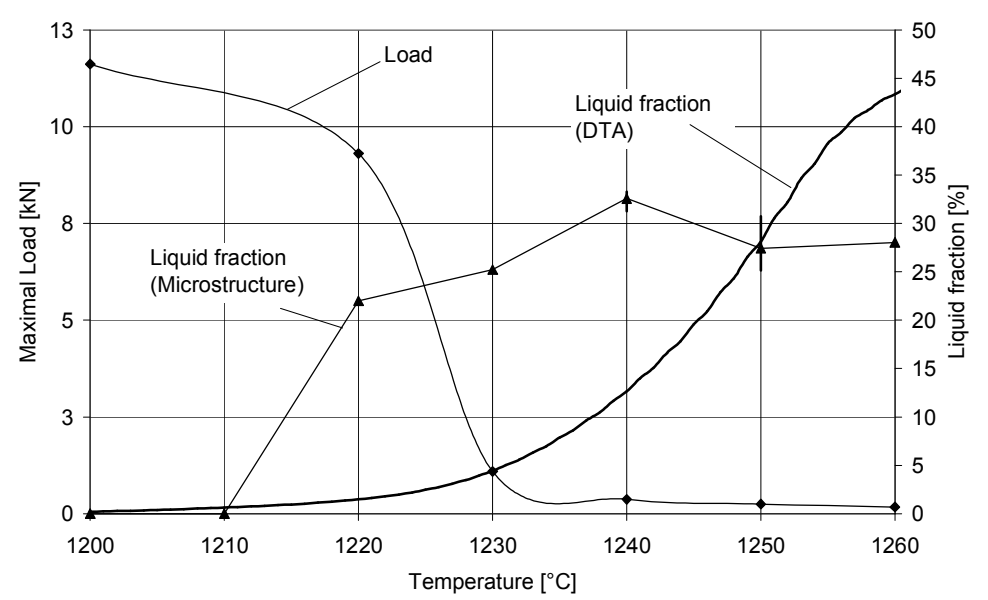

Figure. 7: Load and liquid phase in function of the temperature (heating rate $5 \mathrm{~K} / \mathrm{s}$; deformation rate: $2 \mathrm{~mm} / \mathrm{s}$; holding time: 60s).

\section{Conclusion}

These investigations show the influence of the different parameters on the flow behaviour and on the breakdown of solid skeleton during forming in the semi-solid state. Various physical parameters need to be determined for each steel to determine an optimum process window for thixoforming. The steel X210CrW12 is suitable for Semi-Solid Metalforming due to its properties in the semisolid state: large solidus-liquidus interval, not too high melting temperature and gobular, austenitic grains surrounded by liquid phase. The investigations presented in this paper show the influence of the process parameters on the load development during deformation. It can be summarized that higher thixoforming temperatures, longer holding times, slower heating rates and slower deformation rates lead to lower deformation loads.

\section{References}

[1] G. L. Chiarmetta and M. Rosso (eds.): Proc. $6^{\text {th }}$ Int. Conf. on "Semisolid processing of alloys and composites", Turin, Italy, Sept. 2000, 2000 Brescia, Edimet.

[2] Y. Tsutsui, M. Kiuchi and K. Ichickawa (eds.): Proc. $7^{\text {th }}$ Int. Conf. on "Semisolid processing of alloys and composites", Tsukuba, Japan, Sept. 2002.

[3] W. Püttgen and W. Bleck: Steel Research International, Vol. 8/9 (2004), p.531.

[4] A.A. Kazakov: Advanced Materials and Processes, 157, 3 (2000), p.31.

[5] D.I. Uhlenhaut, J. Kradolfer, W. Püttgen, J.F. Löffler and P.J. Uggowitzer: Acta Materialia, accepted 2006. 
Semi-Solid Processing of Alloys and Composites

doi:10.4028/www.scientific.net/SSP.116-117

Influence of Experimental Parameters on Properties and Microstructure of the Steel X210CrW12 in the Semi-Solid State

doi:10.4028/www.scientific.net/SSP.116-117.209 